\title{
Tethered Aryl Groups Increase the Activity of Anti-Proliferative Thieno[2,3-b]Pyridines by Targeting a Lipophilic Region in the Active Site of PI-PLC
}

\author{
Natalie A. Haverkate ${ }^{1(\mathbb{D})}$, Euphemia Leung ${ }^{2,3}{ }^{(D)}$, Lisa I. Pilkington ${ }^{1}\left(\mathbb{D}\right.$ and David Barker ${ }^{1,4, *(D)}$ \\ 1 School of Chemical Sciences, University of Auckland, Auckland 1010, New Zealand; \\ natalie.haverkate@auckland.ac.nz (N.A.H.); lisa.pilkington@auckland.ac.nz (L.I.P.) \\ 2 Auckland Cancer Society Research Centre, University of Auckland, Auckland 1023, New Zealand; \\ e.leung@auckland.ac.nz \\ 3 Department of Molecular Medicine and Pathology, University of Auckland, Auckland 1023, New Zealand \\ 4 The MacDiarmid Institute for Advanced Materials and Nanotechnology, Victoria University of Wellington, \\ Wellington 6012, New Zealand \\ * Correspondence: d.barker@auckland.ac.nz; Tel.: +64-9-373-7599
}

\section{check for}

updates

Citation: Haverkate, N.A.; Leung, E.; Pilkington, L.I.; Barker, D. Tethered Aryl Groups Increase the Activity of Anti-Proliferative Thieno[2,3-

b]Pyridines by Targeting a Lipophilic Region in the Active Site of PI-PLC. Pharmaceutics 2021, 13, 2020. https:/ / doi.org/10.3390/pharmaceutics1312202

Academic Editors: Peng Zhan,

Shuang-Xi Gu and Edeildo

Ferreira da Silva-Júnior

Received: 29 October 2021

Accepted: 23 November 2021

Published: 26 November 2021

Publisher's Note: MDPI stays neutral with regard to jurisdictional claims in published maps and institutional affiliations.

Copyright: (c) 2021 by the authors. Licensee MDPI, Basel, Switzerland. This article is an open access article distributed under the terms and conditions of the Creative Commons Attribution (CC BY) license (https:/ / creativecommons.org/licenses/by/ $4.0 /)$.

\begin{abstract}
The compounds 2-amino-3-carboxamido-thieno[2,3-b]pyridines have demonstrated excellent anti-proliferative activity against human cancer cell lines, including the triple-negative breast cancer cell line MDA-MB-231. In this study, 81 novel thieno[2,3- $b$ ]pyridines were synthesised in four series to further improve their anti-proliferative activity, in particular by targeting an adjacent lipophilic pocket in the putative target enzyme phosphoinositide phospholipase C (PI-PLC). Overall, it was found that appending a propyl-aryl group at C-5 on 2-amino-3-carboxamido-thieno[2,3$b$ ]pyridine resulted in compounds with potent biological activity, exhibiting $\mathrm{IC}_{50}$ values in the nanomolar range. The propyl linker could be an $\alpha, \beta$-unsaturated ketone or a saturated propyl ketone, but the highest activity was obtained when allylic alcohols were the tether between thieno[2,3$b$ ]pyridine and the appended aryl group, with compound $21 \mathrm{r}$ having $\mathrm{IC}_{50}$ values lower than $50 \mathrm{nM}$. Compounds with one extra carbon in the tether (i.e., a four-atom chain) were found to be considerably less active. Molecular modelling revealed this propyl tether places the newly introduced aryl ring in an untargeted lipophilic pocket within the active site of the phosphoinositide phospholipase C (PI-PLC) enzyme.
\end{abstract}

Keywords: thieno[2,3- $b]$ pyridines; anti-proliferative; $\alpha, \beta$-unsaturated ketones; heterocycles

\section{Introduction}

The anti-proliferative thieno[2,3-b]pyridines have been extensively described in the literature, from their discovery in 2009 as potential inhibitors of PI-PLC [1] to the more recent analogue series that have exhibited increasingly potent anti-proliferative activity against triple-negative breast cancer cell lines, with $\mathrm{IC}_{50}$ values in the $\mathrm{nM}$ range, inducing excellent cell growth inhibition. These findings have increased the interest in these compounds for the development of anti-cancer drugs [2-4].

The mechanism of action by which thienopyridines exert their cytotoxic effect likely involves the inhibition of the phosphoinositide phospholipase C (PI-PLC) enzyme. This enzyme is implicated in many cellular pathways that result in cell proliferation, and its expression is known to be upregulated in many cancers, including the aforementioned triple-negative cancer cell lines [5]. The effects of thienopyridines on cell growth and morphology include severe growth restriction and rounding and blebbing of the plasma membrane. This was corroborated by biological studies that showed that the knockdown of PLC- $\delta_{1}$ and $\delta_{3}$ isoforms in MDA-MB-231 cells had similar effects on cell morphology [6].

Recent studies have shown that thienopyridines interact with a variety of other enzymes, including tyrosyl-DNA phosphodiesterase I (TDP1), $A_{2 A}$ receptor antagonists 
$\left(\mathrm{A}_{2 \mathrm{~A}} \mathrm{AR}\right.$ ), G-protein coupled receptors (GPCRs), $\mathrm{P}_{2} \mathrm{Y}_{12}$ receptors, copper trafficking proteins Atox or tubulin [2,7-13]. Therefore, the anti-proliferative activity of thienopyridines cannot be solely attributed to PI-PLC inhibition, though PI-PLC has been validated as a legitimate target [6].

Other recent studies have also shown that thienopyridine-containing compounds with varying structures have a variety of other biological activities. These include moderate anti-bacterial activity [14], anti-fungal activity [15], and anti-proliferative activity towards multidrug-resistant leukaemia [16]. Therefore, thienopyridines are useful and highly modifiable heterocyclics for pharmaceutical design.

Studies have been undertaken over the past decade to provide an understanding of the effects of features on the thieno[2,3-b]pyridine peripheral structure, enhancing and refining the functional groups that are known to contribute to the biological effects and establishing reliable SAR.

Recently published, the most potent anti-proliferative thieno[2,3-b]pyridines reported are those compounds containing an $N$-benzylpiperidine ring fused to thieno[2,3-b]pyridine (Figure 1, blue) and 2'-Me-3'-Cl and 1'-naphthyl substitution patterns on the arylcarboxamide ring (Figure 1, red). These analogues demonstrated excellent $\mathrm{IC}_{50}$ values between 162 and $644 \mathrm{nM}$ in HCT-116 and MDA-MB-231 cancer cells. This is consistent with the established pattern that $2^{\prime}, 3^{\prime}$-disubstituted aryl carboxamide-containing thienopyridines have the highest anti-proliferative activity among all the studied derivatives and that aromatic rings appropriately positioned off the pyridine ring favourably impact the anti-proliferative activity (Figure 1) [17].

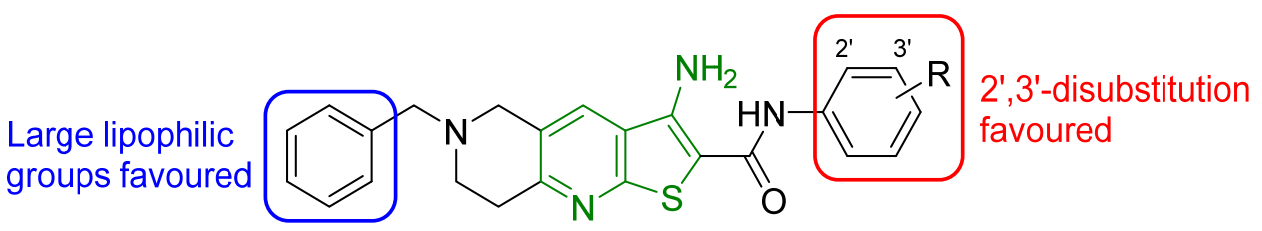

Optimised, most potent thieno[2,3-b]pyridines to date

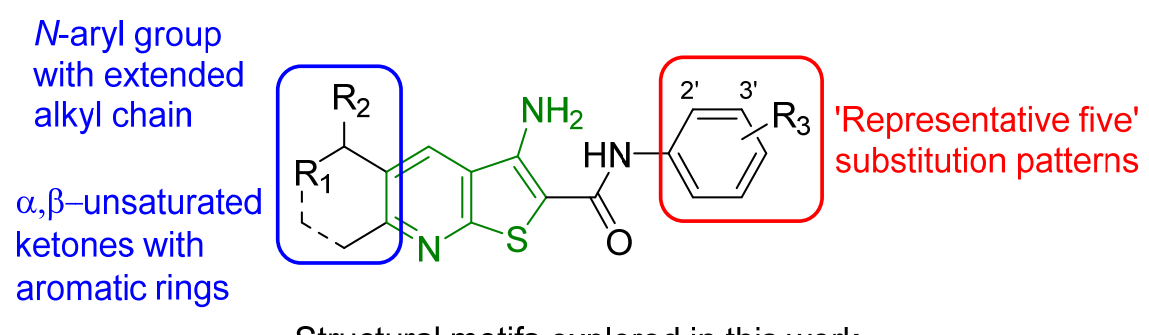

Structural motifs explored in this work

Figure 1. Structure of an N-benzyl thieno[2,3-b]naphthyridine with the general SAR and thienopyridine motif coloured in green (top) and strategies explored in this work to improve the activity of thieno[2,3- $b$ ]pyridines and probe the size limits of the PI-PLC enzyme (bottom).

The discovery that large lipophilic groups appended to the pyridine ring of the thienopyridine enhanced the molecule's biological activity opened up a new area of exploration $[4,17]$. Following on from this, it was of particular importance to identify the motifs that would maximise hydrophobic interactions between thienopyridines and the PI-PLC active site, thereby providing enhanced biological potency. The targeted analogues included those exhibiting variations in the appended lipophilic groups as well as in the length and nature of the tether between these groups and the thienopyridine.

Herein, we report the synthesis, molecular modelling, and anti-proliferative activity of a comprehensive set of thienopyridine derivatives that fulfil the aforementioned proposed modifications (Figure 1), expanding on the potential effects of lipophilic groups appended to the pyridine ring. 


\section{Materials and Methods}

\subsection{Synthesis of the Compounds}

General Details: All reactions were carried out under a nitrogen atmosphere in dry, freshly distilled solvents unless otherwise noted. All NMR spectra were recorded on a Bruker Avance $400 \mathrm{MHz}$ spectrometer at ambient temperature. Chemical shifts are reported relative to the solvent peak of DMSO $\left(\delta 2.50\right.$ for ${ }^{1} \mathrm{H}$ and $\delta 39.5$ for $\left.{ }^{13} \mathrm{C}\right) .{ }^{1} \mathrm{H}$ NMR data are reported as position $(\delta)$, relative integral, multiplicity $(s$, singlet; $d$, doublet; $t$, triplet; q, quartet; dd, doublet of doublets; $\mathrm{dt}$, doublet of triplets; $\mathrm{tt}$, triplet of triplets; $\mathrm{m}$, multiplet; br, broad peak; qd, quartet of doublets), coupling constant $(J, \mathrm{~Hz})$, and the assignment of the atom. ${ }^{13} \mathrm{C}$ NMR data are reported as position $(\delta)$ and assignment of the atom. All NMR assignments were performed with HSQC and HMBC experiments. High-resolution mass spectroscopy (HRMS) was carried out by either chemical ionization (CI) or electrospray ionization (ESI) on a MicroTOF-Q mass spectrometer. Unless noted, chemical reagents were used as purchased. General procedures, synthetic experimental methods and full characterization data (including copies of NMR spectra for all synthesized final compounds) can be found in the Supporting Information.

\subsection{Cell Proliferation Assay}

The synthesised thieno[2,3-b]pyridine final products were measured for their antiproliferative activity against triple-negative breast cancer MDA-MB-231 and colorectal cancer HCT-116 cells (purchased from the American Type Culture Collection) using the ${ }^{3} \mathrm{H}$-thymidine incorporation assay. In total, 3000 cells were seeded in each well of 96 -well plates with varying concentrations of thieno[2,3-b]pyridines for three days. As described in detail previously by Leung et al. [7], the experiments were performed in triplicate with a minimum of two experimental repeats. We added $0.04 \mu \mathrm{Ci}$ of $3 \mathrm{H}$-thymidine to each well $5 \mathrm{~h}$ prior to harvest, after which the cells were harvested onto glass fibre filters using an automated TomTec harvester. The filters were incubated with Betaplate Scint, and thymidine incorporation was determined with a Trilux/Betaplate counter. The effects of the inhibitors on the incorporation of $3 \mathrm{H}$-thymidine into DNA were determined relative to the control samples, with the positive control being a previously known active compound (thieno[2,3-b]pyridine, DJ0081, compound $\mathbf{7 n}$ in Ref 4), and the negative control being cells in a well with no inhibitor.

\subsection{Molecular Modelling}

The thieno[2,3-b]pyridines synthesised in this study were docked into the mammalian PI-PLC- $\delta_{1}$ crystal structure, which was obtained from the Protein Data Bank (PDB ID: 1DJX04, from Rattus norvegicus). The software GOLD suite version 5.8.1 was used to prepare the crystal structure for docking, by the addition of hydrogen atoms and the removal of water molecules, and the co-crystallised ligand (D-myo-inositol-1,4,5-triphosphate, IP3). Basic amino acids were assumed to be protonated, and acidic amino acids deprotonated in order to closely resemble a cell's in vivo environment. The coordinates of the binding pocket were located at the $\mathrm{Ca}^{2+}$ ion, i.e., $\mathrm{x}=126.257, \mathrm{y}=38.394, \mathrm{z}=22.370$, as stated in the literature, with a $10 \AA$ radius. ChemDraw 3D 15.0 was used to build the thieno[2,3$b$ ]pyridines and to perform energy minimisation (MM2) of all structures. For each ligand to be docked, 50 docking runs were allowed at 100\% search efficiency. The scoring functions ChemPLP, GoldScore, ChemScore and ASP were implemented to validate the predicted binding modes and relative energies of the ligands using the GOLD suite version (CSD, Cambridge, UK) 5.8.1.

\section{Results and Discussion}

\subsection{Synthesis of N-Phenylethyl Thieno[2,3-b]Naphthyridine Derivatives (Series 1)}

The purpose of the first series investigated in this work was to explore the theoretical size limit of the thienopyridines and ascertain whether moving the lipophilic aromatic ring further from the thienopyridine core would result in diminished, similar or improved bio- 
logical activity. This resulted in the proposed synthesis of novel $\mathrm{N}$-phenylethyl thieno[2,3$b$ ]naphthyridine compounds, which are longer than the $\mathrm{N}$-Bn analogues by one carbon.

The synthetic methods required to access these analogues proceeded in a manner analogous to that proposed in previous studies using established methods [3,4]. We converted 1-phenethylpiperidin-4-one $\mathbf{1}$ into enolate salt $\mathbf{2}$ using sodium ethoxide and ethyl formate, which was used in the following reaction, without further purification, with cyanothioacetamide in piperidinium acetate solution and provided the required carbonitrile 3. Reaction of $\mathbf{3}$ with sodium carbonate in absolute ethanol, at reflux, with chloroacetamides 4a-e [4] gave the $N$-phenylethyl thieno[2,3-b]naphthyridine derivatives 5a-e (Scheme 1). Five selected chloroarylacetamides with substitution patterns $\mathrm{R}=\mathrm{H}, 2^{\prime}-\mathrm{Me}, 2^{\prime}-\mathrm{Me}-3^{\prime}-\mathrm{Cl}$, $1^{\prime}$-naphthyl and $4^{\prime}$-OMe (hereafter collectively referred to as the 'representative five') were chosen to perform these couplings, as they are typically associated with a range of activities and have previously been used by us to understand the interactions of the compounds with PI-PLC [17]. The 2'-Me-3'-Cl-phenyl and 1'-naphthyl substitution patterns typically impart the best anti-proliferative activity, $4^{\prime}$-OMe-phenyl the worst, whilst $\mathrm{R}=\mathrm{H}$ (phenyl) and $2^{\prime}$-Me-phenyl moderate activity. It was considered that if new compounds displayed activities that did not match our previous results, this might indicate the compounds were interacting with off-target proteins.<smiles>Cc1cccc(CCN2CCC(=O)/C(=C\O[N+]([O-])([O-])C(C)(C)C)C2)c1</smiles><smiles>O=C(CCl)Nc1ccc([Ge])cc1</smiles>

a $R=H$
b $R=2^{\prime}-M e$
c $R=2^{\prime}-M e-3^{\prime}-C l$
d $R=1^{\prime}-$-naphthyl
e $R=4^{\prime}-$ OMe<smiles>[R]c1cccc2ccccc1NC(=O)c1sc3nc4c(cc3c1N)CN(CCc1ccccc1)CC24</smiles>

Scheme 1. Synthesis of thieno[2,3-b]naphthyridines 5a-e. Reagents and conditions: (i) 1phenethylpiperidin-4-one 1 (1.0 equiv.), ethyl formate (1.0 equiv.), $\mathrm{Na}$ (1.0 equiv.), abs. EtOH (cat.), $\mathrm{Et}_{2} \mathrm{O}$, r.t., 24 h, $263 \%$; (ii) salt 2 (1.0 equiv.), cyanothioacetamide (1.0 equiv.), piperidinium acetate soln. (cat.), $\mathrm{H}_{2} \mathrm{O}$, reflux, 24 h, glacial $\mathrm{AcOH}$ (cat.), 24 h, 3 quant.; (iii) carbonitrile 3 (1.0 equiv.), 2-chloro- $N$-arylacetamides 4 a-e (1.0 equiv.), $\mathrm{Na}_{2} \mathrm{CO}_{3}$ (2 equiv.), abs. EtOH, reflux, 48 h, 5a-e 25-71\%.

The structure of all compounds was confirmed using ${ }^{1} \mathrm{H}$ and ${ }^{13} \mathrm{C}$ NMR spectra, infrared spectra, and high-resolution mass spectrometry. Full details and spectra can be found in the Supporting Information.

\subsection{Anti-Proliferative Activity of Series 1}

After the synthesis of series 1, the anti-proliferative activity against two cancer cell lines, MDA-MB-231 and HCT-116, were assessed (Table 1). These cell lines were used as they have previously been shown to be affected by antiproliferative thieno[2,3$b$ ]pyridines [17-20]. Unfortunately, it was found that the antiproliferative activity of thienopyridines 5a-e, overall, was poor. The most active analogue was $2^{\prime}-\mathrm{Me}-3^{\prime}-\mathrm{Cl}-$ phenyl derivative $5 \mathbf{c}$, which showed a maximum of $26.3 \%$ growth inhibition in MDA-MB-231 cells. This anti-proliferative activity was considerably lower than that of the previously tested 2'-Me-3'-Cl-phenyl substituted N-Bn thienopyridine, which showed up to $88.3 \%$ 
growth inhibition in the same cell line. Therefore, whilst this result fit the established SAR leading to the best anti-proliferative activity generally found for $2^{\prime}-\mathrm{Me}-3^{\prime}-\mathrm{Cl}$-phenyl substituted thienopyridines, it showed that extending the distance from the thienopyridine to the phenyl ring from three atoms to four reduced the activity. Molecular modelling later suggested a reduced binding for these longer molecules (see below).

Table 1. Anti-proliferative activity (at $1 \mu \mathrm{M}$ ) of series 1 compounds in HCT-116 and MDA-MB-231 cancer cell lines; ${ }^{a}$ see Section 2.3 for details of controls.

\begin{tabular}{|c|c|c|}
\hline & \multicolumn{2}{|c|}{ Mean Relative Growth of $1 \mu \mathrm{M}$ in Cancer Cell Line (\%) } \\
\hline & HCT-116 & MDA-MB-231 \\
\hline Positive control a & 3.5 & 7.2 \\
\hline Negative control & 100 & 100 \\
\hline $5 a$ & 81.7 & 82.6 \\
\hline $5 b$ & 91.2 & 85.4 \\
\hline $5 c$ & 86.9 & 73.7 \\
\hline $5 d$ & 88.9 & 99.0 \\
\hline $5 e$ & 94.0 & 99.0 \\
\hline
\end{tabular}

Because of the poor anti-proliferative activity of thienopyridines 5a-e, $\mathrm{N}$-phenylethyl compounds were not further investigated. Instead, we focused on series 2 , which comprised previously unexplored $\alpha, \beta$-unsaturated ketone-containing thienopyridines.

\subsection{Synthesis of $\alpha, \beta$-Unsaturated-Ketone Containing Thienopyridine Derivatives (Series 2)}

The next series to be explored, series 2 , was chosen because of the similar atom length from the appended phenyl ring to the thieno[2,3-b]pyridine core in its compounds compared to the previously synthesised (and active) $\mathrm{N}$-Bn thienonaphthyridines (Figure 2) [17]. It was thought that this would result in similarly biologically active compounds, as the cinnamoyl group could potentially fit into the same lipophilic pocket in the PI-PLC active site that was identified in previous molecular modelling studies [21]. It was also established through additional docking studies that the presence of a ketone or alcohol in the 2-position (Figure 2) in cyclic derivatives leads to hydrogen bonding interactions between the oxygen of the ketone and the amino acids ARG549 and LYS438 [18,22]. Therefore, the incorporation of both a carbonyl group in the 2-position and the aromatic ring of the cinnamoyl-type group appended to the pyridine ring was hypothesised to enhance the binding and therefore potentially increase the anti-proliferative activity.<smiles>[R]c1ccc(NC(=O)c2sc3nc4c(cc3c2N)CN(Cc2ccccc2)CC4)cc1</smiles>

$N$-Benzyl thieno[2,3-b]naphthyridine<smiles>[R]c1ccc(NC(=O)c2sc3nc(C)c(C(=O)/C=C/c4ccccc4)cc3c2N)cc1</smiles>

$\alpha, \beta$-Unsaturated ketone thieno[2,3-b]pyridine<smiles>[R]c1ccc(NC(=O)c2sc3nc(C)c(C(O)/C=C/c4ccccc4)cc3c2N)cc1</smiles>

Allylic alcohol thieno[2,3-b]pyridine

Figure 2. Size comparison between N-benzyl, targeted $\alpha, \beta$-unsaturated, and allylic alcohol thieno[2,3-b]pyridines.

It was hypothesised that thienopyridines fulfilling this criterion could be accessed by performing aldol condensations on the methyl ketone carbonitrile fragment, which could then be transformed into a variety of thieno[2,3-b]pyridine $\alpha, \beta$-unsaturated ketone final products. The aforementioned 'representative five' substitution patterns were again 
chosen for the phenyl carboxamide ring. Benzaldehydes that contained polar heteroatoms, e.g., oxygen atoms that could be deprotected giving free phenols, were chosen, so as to potentially increase the solubility of these compounds.

The synthesis of these analogues began with MOM protection of benzaldehyde 6 , which proceeded under standard conditions, supplying di-MOM-ether benzaldehyde 7a. Benzaldehydes 7a-e were reacted in an aldol condensation with known carbonitrile 8 [17] in the presence of a strong base in a methanol/ethanol mixture at r.t. for $24 \mathrm{~h}$ to give the $\alpha, \beta$-unsaturated ketone carbonitriles $\mathbf{9 a}-\mathbf{e}$ (Scheme 2).<smiles>O=Cc1ccc(O)c(O)c1</smiles>

6

\section{(i)}<smiles>COc1ccc(C=O)cc1OC</smiles>

$7 a$

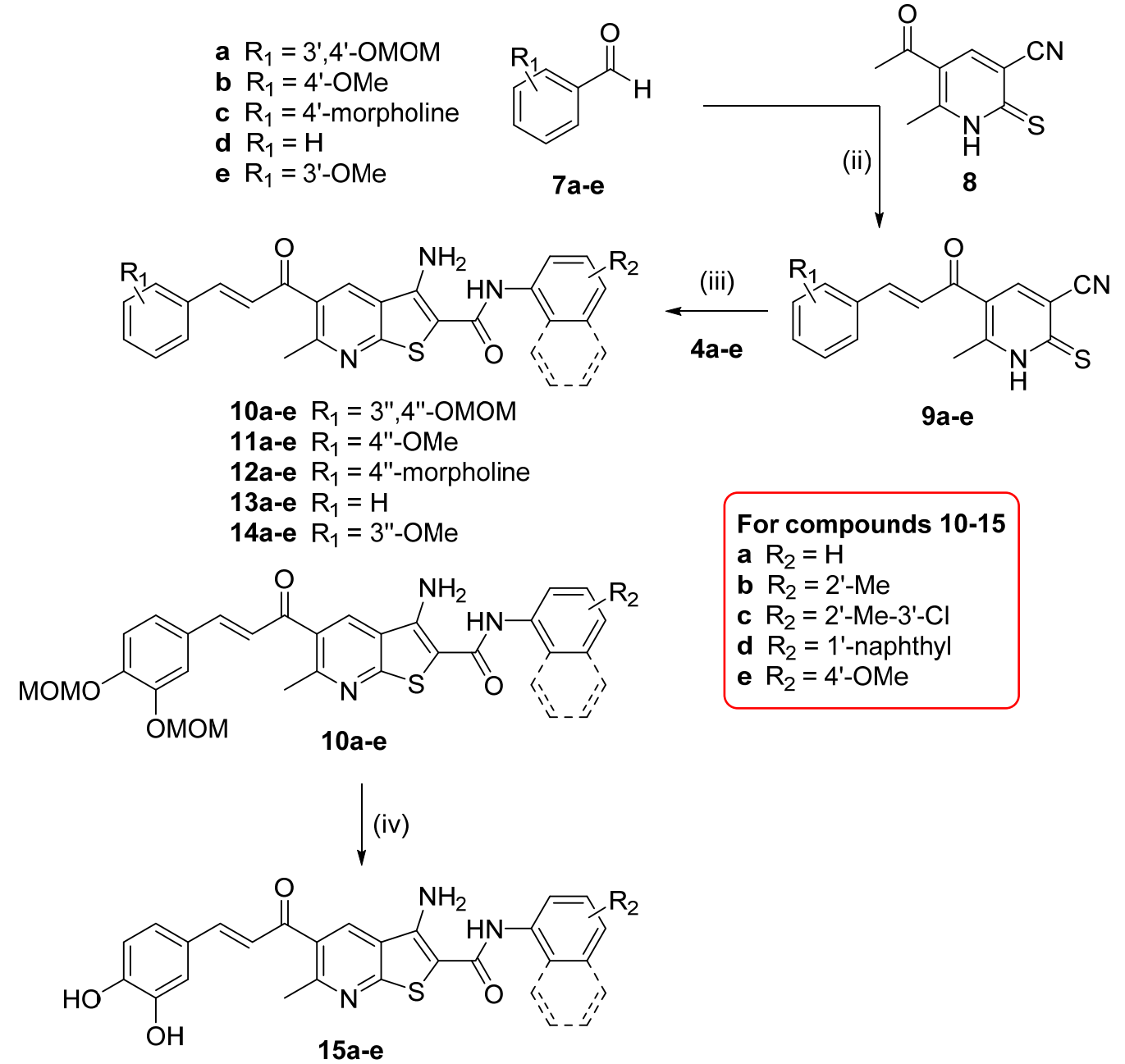

Scheme 2. Synthesis of (E)-3-amino-5-(3-(4'-methoxyphenyl)acryloyl)-6-methyl- $N$-phenylthieno[2,3b]pyridine-2-carboxamides 10a-e, 11a-e, 12a-e, 13a-e, 14a-e and 15a-e. Reagents and conditions. (i) benzaldehyde 6 (1.0 equiv), $\mathrm{MOMCl}$ (2.6 equiv.), DIPEA (4.0 equiv), $\mathrm{CH}_{2} \mathrm{Cl}_{2}$, r.t., 24 h $7 \mathrm{a} 83 \%$; (ii) benzaldehydes $7 \mathrm{a}-\mathbf{e}$ (1.0 equiv.), carbonitrile 8 (1.0 equiv.), $\mathrm{KOH}$ (5.0 equiv.), $\mathrm{EtOH} / \mathrm{MeOH}$, r.t., 24 h; $2 \mathrm{M} \mathrm{HCl}$ 9a-e 60\%-quant; (iii) carbonitriles 9a-e (1.0 equiv.), acetamides 4a-e (1.0 equiv.),

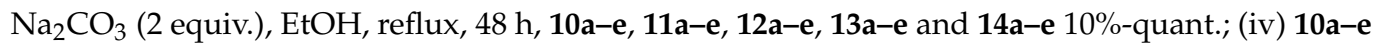
(1.0 equiv.), $6 \mathrm{M} \mathrm{HCl}, \mathrm{MeOH}$, r.t., 24 h $15 a-e$ 38-60\%.

Carbonitriles 9a-e were then coupled with chloroarylacetamides 4a-e in the aforementioned conditions, producing the desired thienopyridines 10a-e, 11a-e, 12a-e, 13a-e 
and 14a-e. Additionally, the removal of the MOM ethers in 10a-e using $6 \mathrm{M} \mathrm{HCl}$ in $\mathrm{MeOH}$ provided the catechols $15 a-e$.

Following the successful preparation of thieno[2,3-b]pyridines 10a-e, 11a-e, 12a-e, 13a-e, 14a-e and 15a-e, a new set of compounds was proposed that would only incorporate the aforementioned $2^{\prime}-\mathrm{Me}-3^{\prime}-\mathrm{Cl}$-phenyl substitution pattern, as these have been proven to consistently show improved anti-proliferative activity. This would enable the synthesis of a large novel series with variation on the new cinnamoyl group, whose activity could then be easily compared with the anti-proliferative activity of the thienopyridines discussed above.

To this end, a range of additional carbonitriles $\mathbf{9 f}-\mathbf{r}$ was subsequently synthesised, incorporating halides and additional groups with various heteroatoms at different positions on the cinnamoyl ring (Scheme 3). The aldol condensations using selected benzaldehydes $\mathbf{7 f}-\mathbf{r}$ and carbonitrile $\mathbf{8}$ proceeded as described above to produce the compounds $\mathbf{9 f}-\mathbf{r}$. Prior to its reaction with $8, \mathrm{MOM}$-ether $\mathbf{7 g}$ was synthesised from alcohol 16 with 85\% yield, employing the aforementioned conditions.<smiles>O=Cc1cccc(O)c1</smiles>

16<smiles>O=Cc1ccccc1</smiles>

7g-r (i)<smiles>COc1cccc(C=O)c1</smiles>

$7 \mathrm{~g}$<smiles>[R]c1cccc(C=CC(=O)c2cc(C)c(=S)[nH]c2CC)c1</smiles>

$\begin{array}{lll}\text { f } R=2 "-O M e & \text { m } R=3 "-C l \\ \text { g } R=3 "-O M O M & \text { n } R=4 "-C l \\ \text { h } R=2 "-C F_{3} & \text { o } R=2 "-B r \\ \text { i } R=2 "-F & \text { p } R=3 "-B r \\ \text { j } R=3 "-F & \text { q } R=4 "-B r \\ \text { k } R=4 "-F & \text { r } R=3 ", 4 "-\text { diOMe } \\ \text { I } R=2 "-C l & & \end{array}$<smiles>COc1cccc(/C=C/C(=O)c2cc3c(N)c(C(=O)Nc4cccc(Cl)c4C)sc3nc2C)c1</smiles>

(iv)<smiles>[R]c1cccc(/C=C/C(=O)c2cc3c(N)c(C(=O)Nc4cccc(Cl)c4C)sc3nc2C)c1</smiles><smiles>Cc1nc2sc(C(=O)Nc3cccc(Cl)c3C)c(N)c2cc1C(=O)/C=C/c1cccc(O)c1</smiles>

Scheme 3. Synthesis of (E)-3-amino- $N$-(3'-chloro-2' -methylphenyl)-5-cinnamoyl-6-methylthieno[2,3$b$ ]pyridine-2-carboxamides 17f-s. Reagents and conditions: (i) benzaldehyde 16 (1.0 equiv), $\mathrm{MOMCl}$ (2.6 equiv.), DIPEA (4.0 equiv), $\mathrm{CH}_{2} \mathrm{Cl}_{2}$, r.t., $24 \mathrm{~h} 7 \mathrm{~g} 85 \%$; (ii) benzaldehydes $7 \mathbf{f}-\mathbf{r}$ (1.0 equiv.), carbonitrile 8 (1.0 equiv.), $\mathrm{KOH}$ (5.0 equiv.), EtOH/ $\mathrm{MeOH}$, r.t., 24 h; $2 \mathrm{M} \mathrm{HCl} \mathrm{9f-r} \mathrm{42-63 \% ;} \mathrm{(iii)} \mathrm{carbonitriles}$ 9f-r (1.0 equiv.), acetamide 4c (1.0 equiv.), $\mathrm{Na}_{2} \mathrm{CO}_{3}$ (2 equiv.), EtOH, reflux, 48 h, 17f-r 52-99\%; (iv) $17 \mathrm{~g}$ (1.0 equiv.), $6 \mathrm{M} \mathrm{HCl}, \mathrm{MeOH}$, r.t., $24 \mathrm{~h} 17 \mathrm{~s}$ quant.

The subsequent synthesis of the coupled thienopyridines $\mathbf{1 7 f}-\mathbf{r}$ similarly proceeded by heating at reflux in ethanol, in the presence of $\mathrm{Na}_{2} \mathrm{CO}_{3}$. Compound 17s was then obtained from acid deprotection of the MOM ethers to complete series 2.

\subsection{Anti-Proliferative Activity of Series 2}

The anti-proliferative activity of series 2 compounds was then assessed, and $\mathrm{IC}_{50}$ values were calculated for the most active compounds. Since the incorporation of the cinnamoyl group was a novel modification for thienopyridines, it was unknown what 
substitution patterns were favoured on the cinnamoyl ring and if the $\alpha, \beta$-unsaturated ketone linker would be tolerated.

Pleasingly, it was found that many of the compounds exhibited excellent anti-proliferative activity (Table 2). The results followed the known trend that $2^{\prime}, 3^{\prime}$-disubstitution patterns on the phenyl carboxamide ring result in higher efficacy, as compounds 10c, 11c, 11d, 12c, 12d, 13c, 13d, 14c, 14d, 15c, 15d and the majority of 17 demonstrated excellent anti-proliferative activity (up to $99.4 \%$ cell growth inhibition when cells were treated with compounds at the concentration of $1 \mu \mathrm{M}$ ). In particular, compound 11d exhibited an $\mathrm{IC}_{50}$ value of $79 \mathrm{nM}$ in HCT-116 cancer cells, which is an improvement with respect to the $\mathrm{IC}_{50}$ of the previously reported most active known thieno[2,3-b]pyridines [4,17].

It was discovered that the phenyl ring in the cinnamoyl group favoured ortho- and parasubstitutions (e.g., 17f, $\mathbf{h}, \mathbf{k}, \mathbf{l}, \mathbf{o}, \mathbf{n})$, with meta-substitution (e.g., $\mathbf{1 3 c}-\mathbf{d}, \mathbf{1 4 c}-\mathbf{d}, \mathbf{1 7} \mathbf{j}, \mathbf{s})$ resulting in more potent activity if smaller groups were utilised.

These results indicated that the hypothesis regarding the effect of a similar distance between the appended phenyl ring and the thienopyridine in series 2 compounds to that in the biologically active $\mathrm{N}$-Bn thienopyridines was correct.

\subsection{Synthesis of Saturated Ketone-Containing Thienopyridine Derivatives (Series 3)}

The excellent anti-proliferative results obtained for the series $2 \alpha, \beta$-unsaturated ketones demonstrated that they were worth investigating further. However, it was noted that $\alpha, \beta$-unsaturated ketones represent a specific moiety (enones) that makes them Pan Assay Interference Compounds (PAINs), having the ability to interact covalently with a variety of targets, including various off-target proteins. That being said, there are FDAapproved drugs currently on the market that incorporate this moiety as a key part of their structure [23]. To expand further on this series and ascertain whether their improved biological activity was due to the enone moiety unselectively reacting with a range of proteins, alkene reduction of the $\alpha, \beta$-unsaturated ketones to obtain saturated ketone products was proposed.

The reduction of enones $\mathbf{1 4 a}-\mathbf{c}, \mathbf{e}$ and $\mathbf{1 7 f}-\mathbf{n}$ proceeded with catalytic hydrogenation using $10 \% \mathrm{Pd} / \mathrm{C}$ in $\mathrm{THF} / \mathrm{MeOH}$, to give the saturated ketones $18 \mathbf{a}-\mathbf{c}, \mathbf{e}$ and $\mathbf{1 9 f}-\mathbf{o}$, thus completing series 3 (Scheme 4). Attempts to perform catalytic hydrogenation on compounds $14 \mathrm{~d}$ and $17 \mathrm{r}$ were unsuccessful. This transformation could also not be performed on bromide-containing analogues, as the conditions led to reductive debromination of the aromatic substituent.

\subsection{Anti-Proliferative Activity of Series 3}

The anti-proliferative activity of series 3 compounds was measured along with the $\mathrm{IC}_{50}$ values for the most active compounds. Pleasingly, as can be seen in Table 3, most series 3 analogues demonstrated anti-proliferative activity similar to that of their unsaturated series 2 counterparts. In particular, 18c maintained the excellent anti-proliferative activity of its parent compound, 14c, as 18c showed $97.8 \%$ cell growth inhibition in HCT-116 cells (compared to $97.4 \%$ growth inhibition for $14 \mathrm{c}$ when added at the concentration of $1 \mu \mathrm{M}$ ).

Compounds 19f-o also showed comparable, if slightly decreased, anti-proliferative activity to that of compounds $\mathbf{1 7 f - o}$, demonstrating that the conversion of the $\alpha, \beta$-unsaturated moiety to the saturated ketone did not negatively impact the anti-proliferative activity. This also demonstrated that any enhanced activity of series 2 compounds was most likely due to the size and/or shape of the molecule rather than to the introduction of an electrophilic enone group. 
Table 2. Anti-proliferative activity (at $1 \mu \mathrm{M}$ ) of series 2 compounds in HCT-116 and MDA-MB-231 cancer cells; ${ }^{\text {a }}$ see Section 2.3 for details of the controls.

\begin{tabular}{|c|c|c|c|c|}
\hline & \multicolumn{2}{|c|}{$\begin{array}{c}\text { Mean Relative Growth of Cancer Cell Line in } 1 \mu \mathrm{M} \text { Solution } \\
\text { of Compound (\%) }\end{array}$} & \multicolumn{2}{|c|}{$\mathrm{IC}_{50}(\mathrm{nM})$} \\
\hline & HCT-116 & MDA-MB-231 & HCT-116 & MDA-MB-231 \\
\hline Positive control a & 3.5 & 7.2 & & \\
\hline Negative control & 100 & 100 & & \\
\hline $10 a$ & 39.9 & 19.0 & 507 & 315 \\
\hline $10 \mathrm{~b}$ & 74.2 & 46.4 & & \\
\hline $10 \mathrm{c}$ & 2.0 & 2.3 & 391 & 403 \\
\hline $10 \mathrm{~d}$ & 28.6 & 13.5 & 687 & 646 \\
\hline $10 \mathrm{e}$ & 78.8 & 41.4 & & \\
\hline $11 a$ & 46.0 & 45.4 & & \\
\hline $11 b$ & 65.8 & 76.7 & & \\
\hline 11c & 3.0 & 5.8 & 154 & 182 \\
\hline 11d & 2.0 & 43.1 & 79 & 762 \\
\hline 11e & 99.2 & 96.3 & & \\
\hline $12 a$ & 7.7 & 19.2 & & \\
\hline $12 b$ & 3.7 & 18.6 & & \\
\hline $12 \mathrm{c}$ & 1.4 & 5.3 & & \\
\hline $12 d$ & 2.5 & 6.9 & & \\
\hline $12 e$ & 82.5 & 51.5 & & \\
\hline $13 a$ & 40.3 & 40.4 & & \\
\hline $13 b$ & 78.7 & 68.3 & & \\
\hline $13 c$ & 1.6 & 2.6 & 461 & 436 \\
\hline $13 d$ & 0.6 & 1.6 & 468 & 379 \\
\hline $13 e$ & 51.0 & 53.2 & & \\
\hline $14 a$ & 43.7 & 39.0 & & \\
\hline $14 b$ & 63.1 & 66.0 & & \\
\hline $14 c$ & 2.6 & 8.6 & 489 & 477 \\
\hline 14d & 2.5 & 8.1 & 531 & 549 \\
\hline $14 \mathrm{e}$ & 60.7 & 60.2 & & \\
\hline $15 a$ & 0.6 & 2.6 & & \\
\hline $15 b$ & 22.8 & 10.7 & & \\
\hline $15 c$ & 0.7 & 1.7 & & \\
\hline $15 d$ & 0.9 & 4.4 & & \\
\hline $15 e$ & 9.1 & 5.2 & & \\
\hline $17 f$ & 1.9 & 3.9 & 242 & 270 \\
\hline $17 \mathrm{~g}$ & 40.0 & 18.1 & & \\
\hline $17 \mathrm{~h}$ & 3.3 & 9.4 & 526 & 507 \\
\hline $17 \mathbf{i}$ & 2.2 & 4.1 & 165 & 189 \\
\hline $\mathbf{1 7} \mathbf{j}$ & 9.3 & 9.0 & 519 & 421 \\
\hline $17 \mathrm{k}$ & 4.3 & 4.4 & 394 & 236 \\
\hline 171 & 3.2 & 5.5 & 537 & 457 \\
\hline $17 \mathrm{~m}$ & 37.2 & 25.5 & & \\
\hline $17 n$ & 7.4 & 10.2 & 515 & 345 \\
\hline $17 \mathrm{o}$ & 4.0 & 8.0 & 535 & 524 \\
\hline $17 p$ & 33.5 & 15.9 & & \\
\hline $17 q$ & 21.3 & 19.0 & 525 & 466 \\
\hline $17 \mathrm{r}$ & 2.4 & 4.2 & 135 & 138 \\
\hline $17 \mathrm{~s}$ & 1.4 & 2.0 & 137 & 103 \\
\hline
\end{tabular}


<smiles>[R7]c1ccc(NC(=O)c2sc3nc(C)c(C(=O)CCc4cccc(OC)c4)cc3c2N)cc1</smiles>

$$
\begin{aligned}
& \text { a } \mathrm{R}_{1}=\mathrm{H} \\
& \text { b } \mathrm{R}_{1}=2^{\prime}-\mathrm{Me} \\
& \text { c } \mathrm{R}_{1}=2^{\prime}-\mathrm{Me}-3^{\prime}-\mathrm{Cl} \\
& \text { e } \mathrm{R}_{1}=4^{\prime}-\mathrm{OMe}
\end{aligned}
$$<smiles>[R]c1ccccc1/C=C/C(=O)c1cc2c(N)c(C(=O)Nc3cccc(C)c3C)sc2nc1C</smiles>

17f-n

19f-n

$\begin{array}{lll}\text { f } \mathrm{R}_{2}=2 "-O M e & \text { k } \mathrm{R}_{2}=4 "-\mathrm{F} \\ \text { g } \mathrm{R}_{2}=3 "-O M O M & \text { I } \mathrm{R}_{2}=2 "-\mathrm{Cl} \\ \text { h } \mathrm{R}_{2}=2 "-\mathrm{CF}_{3} & \text { m } \mathrm{R}_{2}=3 "-\mathrm{Cl} \\ \text { i } \mathrm{R}_{2}=2 "-\mathrm{F} & \text { n } \mathrm{R}_{2}=4 "-\mathrm{Cl} \\ \text { j } \mathrm{R}_{2}=3 "-\mathrm{F} & \end{array}$<smiles>COc1cccc(CCC(=O)c2cc3c(N)c(C(=O)Nc4cccc(Cl)c4C)sc3nc2C)c1</smiles>

Scheme 4. Synthesis of 3-amino-6-methyl-N-phenyl-5-(3-phenylpropanoyl)thieno[2,3-b]pyridine-2-carboxamides 18a-c,e and 19f-o. Reagents and conditions: (i) thieno[2,3-b]pyridines 14a-c,e and 17f-n (1.0 equiv.), 10\% Pd/C (10-20\% weight of

\begin{tabular}{|c|c|c|c|c|}
\hline & \multicolumn{2}{|c|}{$\begin{array}{c}\text { Mean Relative Growth of Cancer Cell Line in } 1 \\
\mu \mathrm{M} \text { Solution of Compound }(\%)\end{array}$} & \multicolumn{2}{|c|}{$\mathrm{IC}_{50} \mathrm{nM}$ (if Present) } \\
\hline & HCT-116 & MDA-MB-231 & HCT-116 & MDA-MB-231 \\
\hline Positive control a & 3.5 & 7.2 & & \\
\hline Negative control & 100 & 100 & & \\
\hline $18 a$ & 83.2 & 58.6 & & \\
\hline $18 b$ & 91.7 & 87.5 & & \\
\hline $18 \mathrm{c}$ & 2.2 & 12.3 & & \\
\hline $18 \mathrm{e}$ & 73.9 & 80.5 & & \\
\hline $19 f$ & 10.5 & 12.8 & 968 & 949 \\
\hline $19 \mathrm{~g}$ & 3.6 & 16.3 & & \\
\hline $19 \mathrm{~h}$ & 32.8 & 33.4 & & \\
\hline $19 \mathrm{i}$ & 4.4 & 8.3 & 124 & 158 \\
\hline $19 j$ & 2.7 & 14.5 & 506 & 564 \\
\hline $19 k$ & 10.0 & 13.9 & 739 & 336 \\
\hline 191 & 5.6 & 13.1 & 393 & 431 \\
\hline $19 \mathrm{~m}$ & 17.3 & 23.8 & 628 & 717 \\
\hline $19 n$ & 46.2 & 31.6 & & \\
\hline 190 & 1.2 & 6.1 & 442 & 518 \\
\hline
\end{tabular}
$\mathrm{SM}), \mathrm{H}_{2}$, MeOH/THF, 48-96 h, 18a-c, e and 19f-n 33\%-quant; (ii) 19g (1.0 equiv.), $6 \mathrm{M} \mathrm{HCl,} \mathrm{MeOH,} \mathrm{r.t.,} 24$ h, 190 quant.

Table 3. Anti-proliferative activity of series 3 compounds ( $1 \mu \mathrm{M}$ concentration) in HCT-116 and MDA-MB-231 cancer cells; a see Section 2.3 for details of the controls. 


\subsection{Synthesis of Allylic Alcohol Containing Thienopyridine Derivatives (Series 4)}

With the knowledge that the enone group was not responsible for the increased bioactivity, we decided to perform the reduction of the ketone as the next transformation. As previously mentioned, alcohols at this position previously demonstrated good antiproliferative activity and better solubility than thieno[2,3-b]pyridine derivatives that do not contain alcohols at this position $[17,18,22]$. In the first synthetic attempt, the required allylic alcohols 20a-e were obtained by Luche reduction of enones $14 \mathbf{a}-\mathbf{e}$ (Scheme 5 ). $\mathrm{CeCl}_{3}$ was used as the Lewis acid, and the reactions were performed in 2:1 THF/MeOH mixtures using $\mathrm{NaBH}_{4}$ as the hydride reducing agent. The remaining series 2 compounds that used solely the $2^{\prime}-\mathrm{Me}-3^{\prime}$-Cl-phenyl substitution pattern on the phenyl carboxamide were then also subjected to the same conditions to produce allylic alcohols $21 \mathbf{f}-\mathbf{r}$ from $\alpha, \beta$-unsaturated ketones $\mathbf{1 7 f - r}$ and complete series 4 .<smiles>COc1cccc(/C=C/C(=O)c2cc3c(N)c(C(=O)Nc4ccccc4Br)sc3nc2C)c1</smiles><smiles>COc1cccc(/C=C/C(O)c2cc3c(N)c(C(=O)Nc4ccccc4Br)sc3nc2C)c1</smiles>

a $\mathrm{R}_{1}=\mathrm{H}$

b $\mathrm{R}_{1}=2^{\prime}-\mathrm{Me}$

c $\mathrm{R}_{1}=2^{\prime}-\mathrm{Me}-3^{\prime}-\mathrm{Cl}$

d $R_{1}=1$ '-naphthyl

e $\mathrm{R}_{1}=4^{\prime}-\mathrm{OMe}$

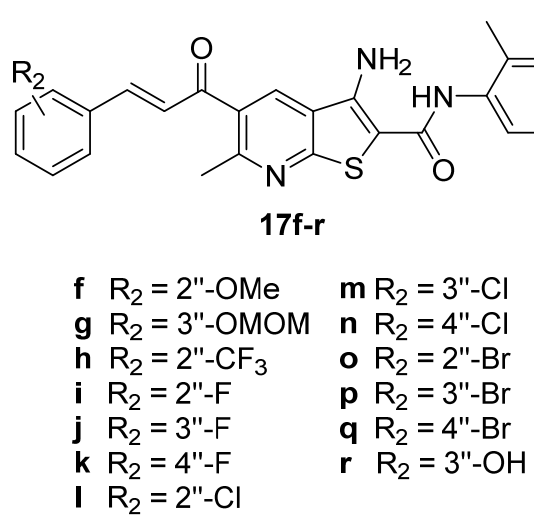

Scheme 5. Synthesis of (E)-3-amino-5-(1-hydroxy-3-phenylallyl)-6-methyl- $N$-phenylthieno[2,3$b$ ]pyridine-2-carboxamides 20a-e and 21f-r. Reagents and conditions: (i) thieno[2,3-b]pyridines 14a-e and 17f-r (1.0 equiv.), $\mathrm{CeCl}_{3}$ (1.1 equiv.), $\mathrm{NaBH}_{4}$ (1 equiv.), 2:1 THF/MeOH, 10-20 min, 20a-e and 21f-r 20\%-quant.

\subsection{Anti-Proliferative Activity of Series 4}

The results if the anti-proliferative assays showed that the allylic alcohols in series 4 also demonstrated excellent anti-proliferative activity, with all compounds except 20e (4'-OMe substituted) exhibiting at least $87.6 \%$ growth inhibition in both HCT-116 and MDA-MB-231 cells when added at $1 \mu \mathrm{M}$ concentration (Table 4). In particular, compounds $21 \mathbf{f}, \mathbf{g}, \mathbf{i}, \mathbf{j}, \mathbf{r}$ also exhibited $\mathrm{IC}_{50}$ values in the low nanomolar range, the lowest being that of 21r (3"-OMe-substituted), which presented IC $_{50}$ values of $25 \mathrm{nM}$ and $51 \mathrm{nM}$ for HCT-116 and MDA-MB-231 cells, respectively. 
Table 4. Anti-proliferative activity of series 4 compounds ( $1 \mu \mathrm{M}$ concentration) in HCT-116 and MDA-MB-231 cancer cells; ${ }^{a}$ see Section 2.3 for details of the controls.

\begin{tabular}{|c|c|c|c|c|}
\hline & \multicolumn{2}{|c|}{$\begin{array}{l}\text { Mean Relative Growth of Cancer Cell } \\
\text { Line in } 1 \mu \mathrm{M} \text { Solution of Compound (\%) }\end{array}$} & \multicolumn{2}{|c|}{$\mathrm{IC}_{50} \mathrm{nM}$ (if Present) } \\
\hline & НCT-116 & MDA-MB-231 & HCT-116 & MDA-MB-231 \\
\hline Positive control ${ }^{a}$ & 3.5 & 7.2 & & \\
\hline Negative control & 100 & 100 & & \\
\hline $20 a$ & 5.6 & 4.8 & 407 & 440 \\
\hline $20 b$ & 8.4 & 8.0 & 501 & 626 \\
\hline $20 c$ & 3.5 & 3.5 & 228 & 341 \\
\hline 20d & 2.5 & 2.7 & 231 & 400 \\
\hline $20 \mathrm{e}$ & 92.2 & 84.1 & & \\
\hline $21 f$ & 1.6 & 3.9 & 55 & 92 \\
\hline $21 g$ & 0.4 & 3.9 & 47 & 109 \\
\hline $21 \mathrm{~h}$ & 1.6 & 4.2 & 128 & 141 \\
\hline $21 \mathbf{i}$ & 1.1 & 2.9 & 32 & 36 \\
\hline $21 j$ & 1.8 & 4.5 & 50 & 104 \\
\hline $21 k$ & 2.2 & 4.1 & 94 & 131 \\
\hline 211 & 1.6 & 3.7 & 136 & 140 \\
\hline $21 \mathrm{~m}$ & 1.9 & 5.7 & 130 & 181 \\
\hline $21 n$ & 2.2 & 4.9 & 137 & 168 \\
\hline 210 & 1.2 & 3.3 & 114 & 138 \\
\hline $21 p$ & 3.0 & 12.4 & 156 & 223 \\
\hline $21 q$ & 2.2 & 5.4 & 146 & 317 \\
\hline $21 \mathrm{r}$ & 0.4 & 3.5 & 25 & 51 \\
\hline
\end{tabular}

Overall, series 4 compounds showed the best anti-proliferative activity out of all the series tested and appear to be among the best performing thieno[2,3-b]pyridines to date. The improved activity of the allylic alcohols with respect to the $\alpha, \beta$-unsaturated ketone derivatives could be due to the decreased planarity of the compounds and/or to improved aqueous solubility due to the introduction of the more polar hydroxyl group. The cLogP values of the alcohols 20/21 were on average 0.7 lower than those of their ketone 14/17 counterparts, providing them with improved drug-like properties.

\subsection{Molecular Modelling Study}

The 81 thieno[2,3-b]pyridines synthesised in this study were also docked into the mammalian PI-PLC- $\delta_{1}$ crystal structure to further investigate the effect of new substitution patterns on the docking and visualise the results. Docking studies were performed using the four scoring functions in the GOLD software suite. Thienopyridines are known to form hydrogen bonds with amino acid residues in the PLC- $\delta_{1}$ active site, commonly including GLU341, HIS311, HIS356, ARG549 and LYS438, and many of these interactions were observed in this molecular modelling study.

As can be seen in Figure 3, the docking conformation of the new $\alpha, \beta$-unsaturated ketones was comparable to that of the previously synthesised $N$-Bn analogues, with the $\mathrm{N}$-Bn ring and the cinnamoyl group consistently docked into the narrow hydrophobic cleft shown in the bottom right of the Figure. The similarity in binding suggests this is why these analogues have comparable activity. 


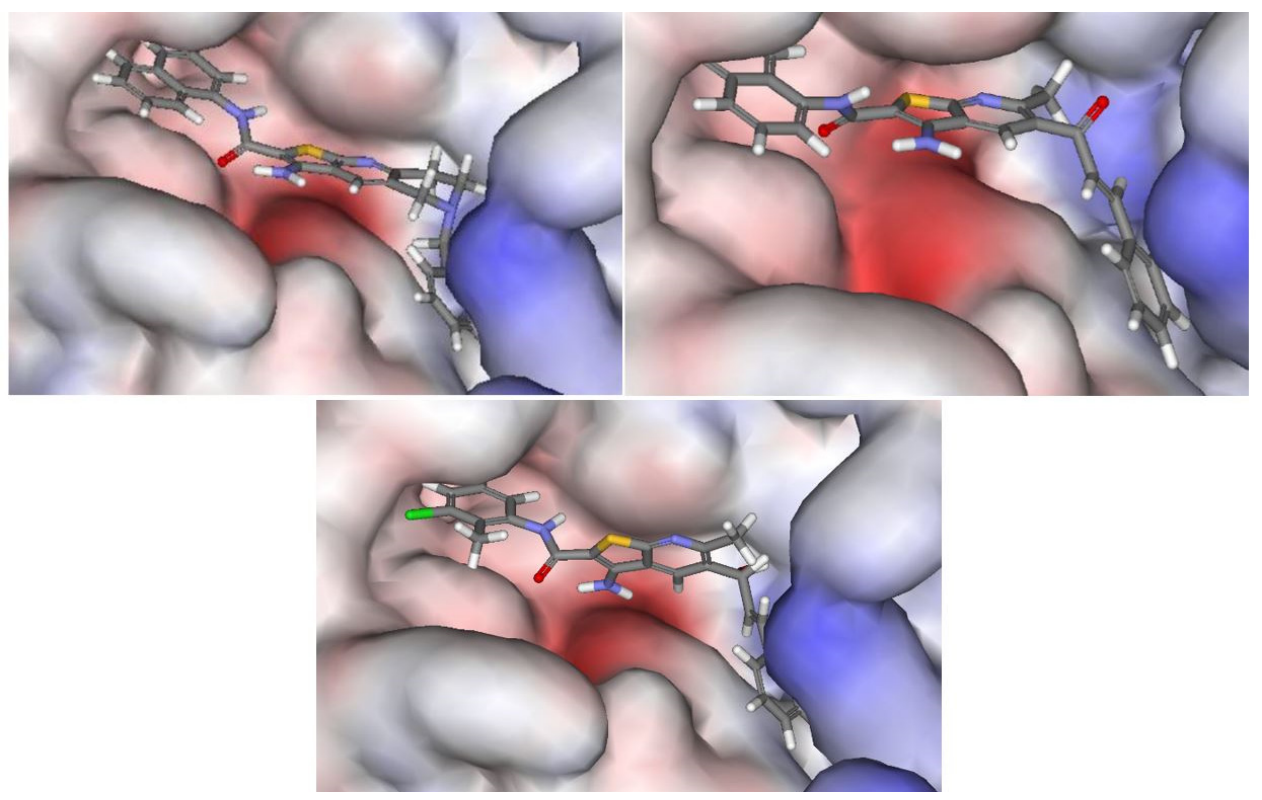

Figure 3. The docked configuration of a naphthyl-substituted $N$-Bn thienopyridine (top left), the novel enone 13d (top right) and the novel allylic alcohol 21r (bottom centre) in the binding site of PLC- $\delta_{1}$ using ChemPLP. The naphthyl group is docked in the upper left hydrophobic pocket, and the $\mathrm{N}$-Bn/cinnamoyl ring in the bottom left hydrophobic pocket. Red areas depict a partial negative charge on the surface, blue areas depict a partial positive charge, and grey areas are neutral/lipophilic.

Multiple new $\pi$ and hydrogen bond interactions were also observed between the new cinnamoyl group, substitutions on the cinnamoyl ring (e.g., hydroxy groups) and amino acid residues of the PLC- $\delta_{1}$ active site (Figure 3 ). The scoring functions consistently gave high scores for the enones, and this was conserved between the algorithms, which was consistent with the excellent anti-proliferative activity of these compounds. The enone and enone derivatives were found to have mean ChemPLP scores between 82.44 and 90.04.

It was also consistently observed that para-substitution $\left(4^{\prime}-\mathrm{OMe}\right)$ on the phenyl carboxamide rings led to a decrease in scoring across all the algorithms compared to the other 'representative five' substitution patterns, which was in line with previous findings. This was observed for all the docked derivatives that incorporated the $4^{\prime}$-OMe-phenyl substitution pattern. In docking studies, this was proposed to be due to the $4^{\prime}$-OMe group pushing the thieno[2,3- $b$ ]pyridines out of their normal central position in the active site, which subsequently results in the loss of important hydrophobic and hydrogen bonding interactions between the ligand and the active site.

The observation of the interactions between the allylic alcohol 21r (which had excellent anti-proliferative activity) and the PLC- $\delta_{1}$ active site (Figures 4 and 5) showed that, although a unfavourable donor-donor interaction was observed, many $\pi$ and hydrogen bond interactions were also present around the core structure. Notably, the $3^{\prime \prime}$-OMe group on the cinnamoyl phenyl ring was involved in new hydrogen bond interactions with LEU389 and LYS440, and the allylic alcohol was involved in interactions with ARG549 and SER522, which were all highly favourable. These interactions were also apparent in the parent enone 17s, though the enone carbonyl hydrogen bonded with different amino acids, which provides a possible explanation as to why enone 17s also showed an excellent anti-proliferative activity. These additional interactions could also help to explain why this series of thieno[2,3- $b$ ]pyridine analogues, particularly the allylic alcohols, showed such good anti-proliferative activity overall. 


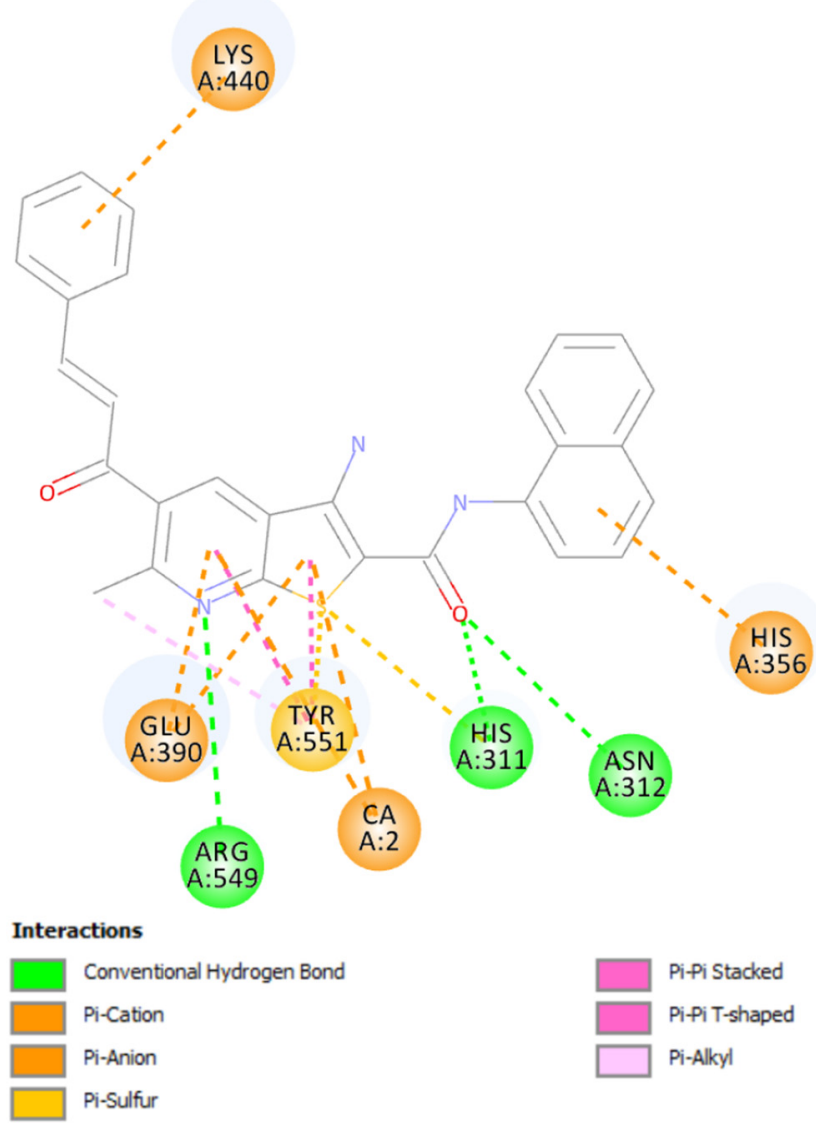

Figure 4. Observed interactions between 13d and the PLC- $\delta_{1}$ active site (using ChemPLP algorithm in GOLD).

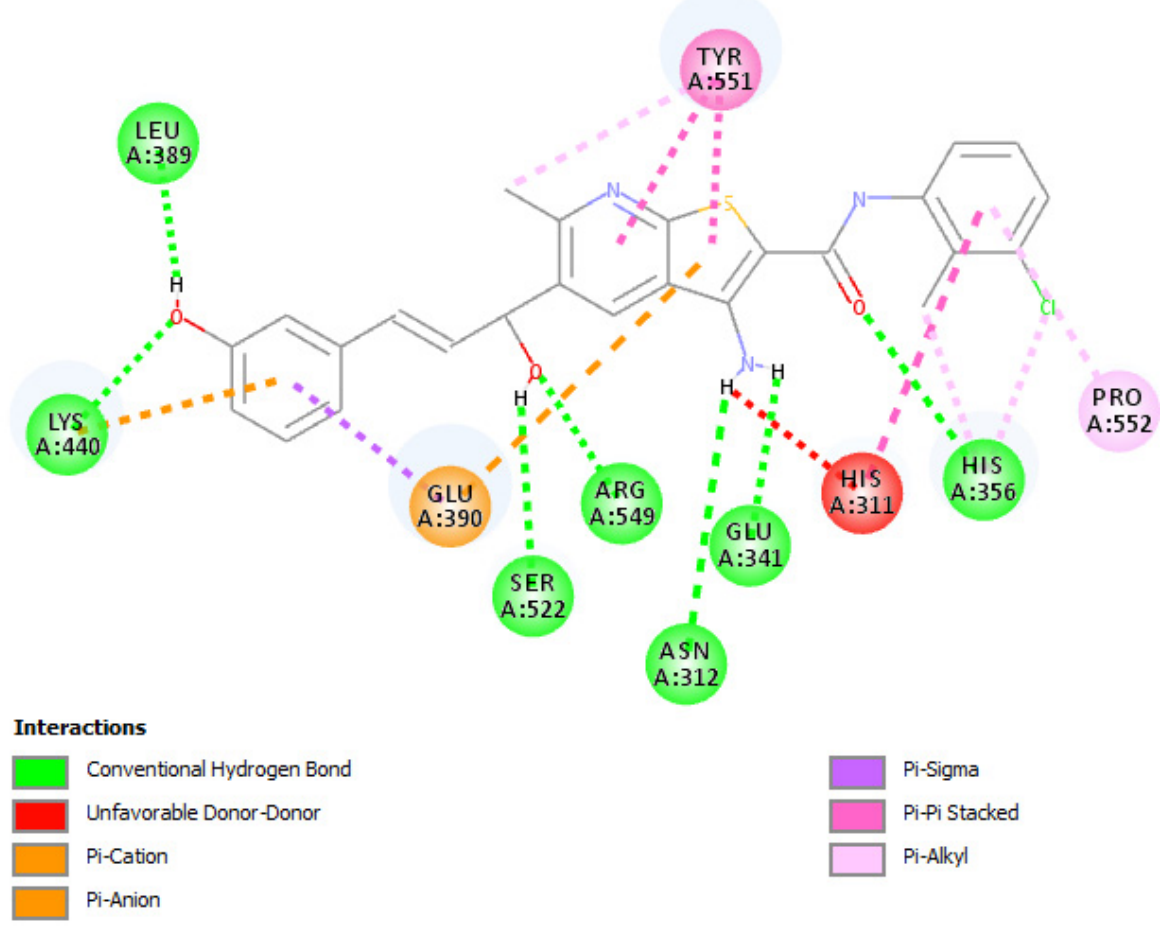

Figure 5. Observed interactions between 21r and the PLC- $\delta_{1}$ active site (using ChemPLP algorithm in GOLD). 


\section{Conclusions}

This study focused on the preparation of novel thieno[2,3-b]pyridines with additional tethered aryl groups reaching into a lipophilic pocket within the PI-PLC active site. These new compounds were prepared to ascertain the size limit and improve the anti-proliferative activity of this class of compounds. In total, 81 compounds in four series were synthesised, tested for their anti-proliferative activity and studied using molecular modelling by docking them into the active site of PLC- $\delta_{1}$. It was found that the $N$-phenylethyl thieno[2,3$b$ ]naphthyridines 5a-e (series 1 ) demonstrated poor antiproliferative activity, which was hypothesised to be due to increased molecular length, which leads to poor binding with the target enzyme. This reduced binding was suggested by the disputed docking poses in the active site between the fitness functions. In contrast, many of the enones 10a-e, 11a-e, 12a-e, 13a-e, 14a-e and 15a-e (series 2), showed excellent anti-proliferative activity. Their derivatives, saturated ketones 18a-c,e and 19f-o (series 3 ) and allylic alcohols 20a-e and 21f-r (series 4), also demonstrated comparable activity and exhibited mean relative cell growth between 1.63 and $62.75 \%$, surpassing in activity the thienopyridines previously considered as the most active. Overall, we found that the incorporation of any propyl-aryl group such as enones, saturated ketones or allylic alcohols increased the compounds' anti-proliferative activity. These results show that the judicious placement of an aryl group in an adjacent lipophilic pocket in the active site of PI-PLC leads to an increase in thienopyridines' overall activity.

Supplementary Materials: The experimental procedures and characterisation data for all synthesised compounds are available online at https:/ / www.mdpi.com/article/10.3390/pharmaceutics13122020/s1.

Author Contributions: Conceptualization, L.I.P. and D.B.; methodology, N.A.H., E.L., L.I.P. and D.B.; validation, N.A.H. and E.L.; investigation, N.A.H. and E.L.; resources, E.L., L.I.P. and D.B.; writing—original draft preparation, N.A.H. and L.I.P. writing—review and editing, N.A.H., E.L., L.I.P. and D.B.; supervision, L.I.P. and D.B.; project administration, L.I.P. and D.B.; funding acquisition, E.L., L.I.P. and D.B. All authors have read and agreed to the published version of the manuscript.

Funding: This research was funded by Cancer Society New Zealand.

Institutional Review Board Statement: Not applicable.

Informed Consent Statement: Not applicable.

Data Availability Statement: Data are contained within the article.

Acknowledgments: The authors would like to acknowledge financial support for this work from the University of Auckland (doctoral scholarship for N.A.H.).

Conflicts of Interest: The authors declare no conflict of interest.

\section{References}

1. Reynisson, J.; Court, W.; O’Neill, C.; Day, J.; Patterson, L.; McDonald, E.; Workman, P.; Katan, M.; Eccles, S.A. The identi-fication of novel PLC- $\gamma$ inhibitors using virtual high throughput screening. Bioorg. Med. Chem. 2009, 17, 3169-3176. [CrossRef] [PubMed]

2. Arabshahi, H.J.; van Rensburg, M.; Pilkington, L.I.; Jeon, C.Y.; Song, M.; Gridel, L.-M.; Leung, E.; Barker, D.; Vuica-Ross, M.; Volcho, K.P.; et al. A synthesis, in silico, in vitro and in vivo study of thieno[2,3-b]pyridine anticancer analogues. MedChemComm 2015, 6, 1987-1997. [CrossRef]

3. Leung, E.; Hung, J.M.; Barker, D.; Reynisson, J. The effect of a thieno[2,3-b]pyridine PLC- $\gamma$ inhibitor on the proliferation, morphology, migration and cell cycle of breast cancer cells. MedChem Comm 2014, 5, 99-106. [CrossRef]

4. Leung, E.; Pilkington, L.I.; van Rensburg, M.; Jeon, C.Y.; Song, M.; Arabshahi, H.J.; De Zoysa, G.H.; Sarojini, V.; Denny, W.A.; Reynisson, J.; et al. Synthesis and cytotoxicity of thieno[2,3-b]quinoline-2-carboxamide and cycloal-kyl[b]thieno[3,2-e]pyridine-2carboxamide derivatives. Bioorg. Med. Chem. 2016, 24, 1142-1154. [CrossRef]

5. Sala, G.; Dituri, F.; Raimondi, C.; Previdi, S.; Maffucci, T.; Mazzoletti, M.; Rossi, C.; Iezzi, M.; Lattanzio, R.; Piantelli, M.; et al. Phospholipase C $\gamma 1$ Is Required for Metastasis Development and Progression. Cancer Res. 2008, 68, 10187-10196. [CrossRef]

6. Reynisson, J.; Barker, D.; Jaiswal, J.K.; Denny, W.A.; Baguley, B.C.; D’Mello, S.A.N.; Leung, E.Y. Evidence that phos-pholipase C is involved in the antitumour action of NSC768313, a new thieno[2,3-b]pyridine derivative. Cancer Cell Int. 2016, 16, 18. [CrossRef] 
7. Leung, E.; Patel, J.; Hollywood, J.A.; Zafar, A.; Tomek, P.; Barker, D.; Pilkington, L.I.; van Rensburg, M.; Langley, R.J.; Helsby, N.A.; et al. Validating TDP1 as an Inhibition Target for the Development of Chemosensitizers for Camptothecin-Based Chemotherapy Drugs. Oncol. Ther. 2021, 9, 541-556. [CrossRef]

8. Arabshahi, H.J.; Leung, E.; Barker, D.; Reynisson, J. The development of thieno[2,3-b]pyridine analogues as anticancer agents applying in silico methods. MedChem Comm 2014, 5, 186-191. [CrossRef]

9. Zafar, A.; Sari, S.; Leung, E.; Pilkington, L.I.; Van Rensburg, M.; Barker, D.; Reynisson, J. GPCR Modulation of Thieno[2,3b]pyridine Anti-Proliferative Agents. Molecules 2017, 22, 2254. [CrossRef]

10. Eurtivong, C.; Semenov, V.; Semenova, M.; Konyushkin, L.; Atamanenko, O.; Reynisson, J.; Kiselyov, A. 3-Amino-thieno[2,3b]pyridines as microtubule-destabilising agents: Molecular modelling and biological evaluation in the sea urchin embryo and human cancer cells. Bioorg. Med. Chem. 2017, 25, 658-664. [CrossRef]

11. Romagnoli, R.; Baraldi, P.G.; Salvador, M.K.; Preti, D.; Tabrizi, M.A.; Bassetto, M.; Brancale, A.; Hamel, E.; Castagliuolo, I.; Bortolozzi, R.; et al. Synthesis and Biological Evaluation of 2-(Alkoxycarbonyl)-3-Anilinobenzo[b]thiophenes and Thieno[2,3b]pyridines as New Potent Anticancer Agents. J. Med. Chem. 2013, 56, 2606-2618. [CrossRef]

12. Katritch, V.; Jaakola, V.-P.; Lane, J.R.; Lin, J.; Ijzerman, A.P.; Yeager, M.; Kufareva, I.; Stevens, R.C.; Abagyan, R. Structure-Based Discovery of Novel Chemotypes for Adenosine A2A Receptor Antagonists. J. Med. Chem. 2010, 53, 1799-1809. [CrossRef]

13. Binsaleh, N.K.; Wigley, C.A.; Whitehead, K.A.; van Rensburg, M.; Reynisson, J.; Pilkington, L.I.; Barker, D.; Jones, S.; DempseyHibbert, N.C. Thieno[2,3-b]pyridine derivatives are potent anti-platelet drugs, inhibiting platelet activation, aggregation and showing synergy with aspirin. Eur. J. Med. Chem. 2018, 143, 1997-2004. [CrossRef]

14. Elsherif, M.A. Antibacterial evaluation and molecular properties of pyrazolo[3,4-b] pyridines and thieno[2,3-b]pyridines. J. Appl. Pharm. Sci. 2021, 11, 118-124.

15. Ibrahim, O.F.; Bakhite, E.A.; Metwally, S.A.M.; El-Ossaily, Y.A.; Abdu-Allah, H.H.M.; Al-Taifi, E.A.; Kandel, M. Synthesis, Characterization, and Antifungal Activity of Some New Thieno[2,3-b]pyridines Incorporating Quinazoline or Ben-zimidazole Moiety. Russ. J. Bioorg. Chem. 2021, 47, 918-928. [CrossRef]

16. Al-Trawneh, S.A.; Tarawneh, A.H.; Gadetskaya, A.V.; Seo, E.-J.; Al-Ta'Ani, M.R.; Al-Taweel, S.A.; El-Abadelah, M.M. Synthesis and Cytotoxicity of Thieno[2,3-b]Pyridine Derivatives Toward Sensitive and Multidrug-Resistant Leukemia Cells. Acta Chim. Slov. 2021, 68, 458-465. [CrossRef]

17. Haverkate, N.A.; van Rensburg, M.; Kumara, S.; Reynisson, J.; Leung, E.; Pilkington, L.I.; Barker, D. Improving the solubility of anti-proliferative thieno[2,3-b]quinoline-2-carboxamides. Bioorganic Med. Chem. 2021, 37, 116092. [CrossRef] [PubMed]

18. van Rensburg, M.; Leung, E.; Haverkate, N.A.; Eurtivong, C.; Pilkington, L.I.; Reynisson, J.; Barker, D. Synthesis and antiproliferative activity of 2-chlorophenyl carboxamide thienopyridines. Bioorg. Med. Chem. Lett. 2017, 27, 135-138. [CrossRef]

19. Zafar, A.; Pilkington, L.I.; Haverkate, N.A.; Van Rensburg, M.; Leung, E.; Kumara, S.; Denny, W.A.; Barker, D.; Alsuraifi, A.; Hoskins, C.; et al. Investigation into Improving the Aqueous Solubility of the Thieno[2,3-b]pyridine Anti-Proliferative Agents. Molecules 2018, 23, 145. [CrossRef]

20. Barker, D.; Pilkington, L.; Haverkate, N.; Van Rensburg, M.; Reynisson, J.; Leung, E. Synthesis of 3-Amino-2-carboxamide Tetrahydropyrrolo[2,3-b]quinolines. Synlett 2016, 27, 2811-2814. [CrossRef]

21. Haverkate, N.A. Synthesis and Investigation of Anti-proliferative Thieno[2,3-b]pyridine Derivatives with Enhanced Solubility. Master's Thesis, University of Auckland, Auckland, New Zealand, 2017.

22. Hung, J.M.; Arabshahi, H.J.; Leung, E.; Reynisson, J.; Barker, D. Synthesis and cytotoxicity of thieno[2,3-b]pyridine and furo[2,3b]pyridine derivatives. Eur. J. Med. Chem. 2014, 86, 420-437. [CrossRef] [PubMed]

23. Jackson, P.A.; Widen, J.C.; Harki, D.A.; Brummond, K.M. Covalent Modifiers: A Chemical Perspective on the Reactivity of $\alpha, \beta$-Unsaturated Carbonyls with Thiols via Hetero-Michael Addition Reactions. J. Med. Chem. 2017, 60, 839-885. [CrossRef] [PubMed] 